\title{
«Large-scale risks and technological change: What about limited liability? »
}

\author{
$\underline{\text { Auteurs }}$ \\ Julien Jacob, Sandrine Spaeter
}

Document de Travail $\mathrm{n}^{\circ} 2010$ - 12

Avril 2010

Faculté des sciences économiques et de gestion

Pôle européen de gestion et d'économie (PEGE) 61 avenue de la Forêt Noire F-67085 Strasbourg Cedex

Secétariat du BETA Géraldine Manderscheidt Tél. : (33) 0368852069 Fax : (33) 0368852070 g.manderscheidt@unistra.fr http://cournot2.u-strasbg.fr/beta 


\title{
Large-scale risks and technological change: What about limited liability?*
}

\author{
Julien $\mathrm{JACOB}^{\dagger} \quad$ Sandrine SPAETER ${ }^{\ddagger}$
}

April 26, 2010

\begin{abstract}
We consider a firm that has to choose a technology to produce a given good. This technology drives a multiplicative large-scale risk of incident for Society: the total potential level of damage increases with the level of activity. Contrary to what is often argued in the literature, we show that limited liability can be more incentive for technical change than an unlimited liability rule, depending on the magnitude of the technological change and on the firm's size. In a second part of the paper, taxes are introduced. We show how manipulating the tax rate with respect to the technological choice made by the firm still enlarges the set of parameters that lead to technological change under a limited liability rule. Our normative results provide some arguments in favor of the limited liability rule, often considered as the main explanation of partial large-scale risk internalization by firms.
\end{abstract}

Keywords: Technological risk, limited liability, incentives, technical choice, taxes.

JEL Classification: D81, H23, K39, Q55.

*We thank Claude Fluet, Bruno Deffains and Patrick Llerena for very helpful comments on earlier versions. Participants in the Strasbourg-Nancy BETA-Seminar, and in the Paris 1 Seminar on Environmental Economics and Natural Resources are also acknowledged.

†BETA, UMR 7522 CNRS/Nancy-Université. 13, Place Carnot, C.O. 26, 54035 NANCY CEDEX. E-mail: julien.jacob@univ-nancy2.fr

${ }_{\ddagger}^{\ddagger}$ BETA, UMR 7522 CNRS/Nancy-Université. 13, Place Carnot, C.O. 26, 54035 NANCY CEDEX. E-mail: spaeter@unistra.fr 


\section{Introduction}

Limiting the losses of a firm in the case of bankruptcy to her net value permits her to innovate and to levy funds for research and development in some rather reassuring economic and legal context. Since innovation is a key factor of the economic growth, the limited liability rule seems to be a good legal rule in the light of only these arguments. Nevertheless, it is common knowledge, since Shavell (1986)'s work in particular, that a limited liability rule may also induce either partial risk internalization by firm or overinvestment in risky activities. Having to pay only up to the net value of their assets in the case of an incident, some firms and their shareholders may have some interest to conduct some projects that have a negative net present value when taking into account all the technological risk that is tranferred to Society. In order to countervail these negative effects, some papers focus on the usefulness of a rule that would extend the financial liability to the partners of a responsible firm. This partner (a bank for instance) will have to pay for extra damages if the firm is bankrupted and cannot pay up to a certain amount (see Klimek, 1990, for some practical cases involving US banks in the eighteens). Such a rule should increase the available funds for compensation. But it may also lessen the incentives of firms to invest in prevention, for their financial responsibility is moved towards the other operators (Beard, 1990; Pitchford, 1995 ; Boyd and Ingberman, 1997; Boyer and Laffont, 1997; Dionne and Spaeter, 2003; Hiriart and Martimort, 2006). This last literature assumes that technological choice is exogenous to the decision process of the firm. Thus it does not allow it to consider the role that technological change could play in the technological risk management. Incentives driven by technological change are not considered despite the fact that firms are, in practice, willing to engage in such a process.

Technological change in the framework of pollution control is considered by Milliman and Prince (1989). Concerning R\&D programs, some analyses take into account the imitation abilities of firms that compete on a given market (Fischer et al., 2003; Parry, 1995), the trade-off between a more productive technology, at given emissions, and a less pollutant one (Magat 1978, 1979), while others focus on the technological 
choice of firms within the framework of imperfect competition (à la Bertrand) (Requate, 1998). These analyses take the liability context as given, ignoring the contributions of the economic analysis of liability. The agent is considered as always financially solvent whatever the state of nature that occurs, and she makes her choices in an unlimited liability context. If unlimited liability is proned by some economists and some jurists from a normative point of view (Faure, 1995; Hansmann and Kraakman, 1991; Halpern, Trebilcock and Turnbull, 1980), it is much more complicate to implement it in practice. Indeed Alexander (1992, p. 389) writes "To the extent that the proposal could constitutionally be implemented, enforcement would raise substantial procedural obstacles". For some practical reasons, the law could even be unenforceable (think about out-of-state shareholders would should be identified) and implementation costs can be higher than the net benefit for Society ${ }^{1}$. In the particular case of large-scale (or catastrophic) risks (Schmitt and Spaeter, 2007, for nuclear risks for instance), the efficiency of unlimited liability in terms of risk internalization can still be put in doubt. Desasters following a dramatic technological accident can be so high that no firm and no operator of her, even if well identified, is able to pay for compensation and restoration. Thus the liability can be as unlimited as possible, victims will never be fully indemnified. Even so, it can take a very long time until a legal court obtains all the information and takes a decision about who should pay and how much. ${ }^{2}$

In this paper, we show that limited liability does not always lead to less riskinternalization or poorer incentives to change for a safer technology. Moreover, taxes can still improve the incentives driven by limited liability. Our analysis is conducted in two stages. First, we focus on the incentives that unlimited and limited liability make emerge in terms of technological change ${ }^{3}$. The first rule implies that the potential injurer (the firm and her shareholders) will always have to pay for all the damage caused by her

\footnotetext{
${ }^{1}$ See also Easterbrook and Fischel (1985), and Grundfest (1992).

${ }^{2}$ In a rather different framework and by considering, in particular that safety investments can impact the level of damage per unit of production, Boyd and Ingberman (1994) also provide some arguments in favor of capped damages.

${ }^{3}$ Contrary to Magat $(1978,1979)$ and Fischer et al. $(2003)$, we do not consider technologicall innovation. The firm chooses between two existing technologies, an "old" technology and a new one (just arrived on the market).
} 
activity. Thus her profit may be negative. The second rule limits the ex post liability of the firm for she will have to pay for damages only up to her present net value. Her lowest possible profit equals zero and it corresponds to bankruptcy state. In such a situation, which may occur after a huge incident, the firm and her shareholders will not have to compensate victims out of their pocket. In a second part of the paper, we associate taxes with a limited liability rule in order to enlarge the set of parameters for which a firm is willing to move from a default technology to a safer one.

One originality of our simple model deals with this combination of rules and taxes. Even if, in practice, it is common use, such a setting has never been analyzed from a normative point of view. One can learn about the behaviors it yields in practice, for instance by observing strategies within the industries, but one does not know how it can help getting closer to socially optimal behaviors in terms of technological change and of activity levels. Second, considering that the risk driven by the activity of the firm is simultaneously affected by the technological choice and the level of production is also an important point of our analysis. Many models relative to large-scale risk management in the literature assume that the risk of incident is affected by some investment in prevention (which could be, in a certain manner, compared to "small" technological change) but not by production. In our setting, a technological change induces also a change in the marginal cost of production and the optimal level of activity becomes a best response to the optimal technological choice. It is important to notice that a safer technology leads to a higher production costs reflecting the past $\mathrm{R} \& \mathrm{D}$ process that permitted to develop this new technology. This is rather different from the literature focusing on technologies that lead to a reduction of the abatement costs of some pollution. Moreover, taxes conditioned by the adopted technology are considered in the last section. This would not be possible if technological change were only resumed by a change in the incident probability. Thus our setting is more general than just assuming, for a given level of activity, a decrease of the probability of incident obtained thanks to some efforts done by the firm. Shavell $(1980,2004)$ also considers that the damage is affected by the level of activity, but recall that he considers the negligence rule, while we focus on limited liability. 
A last important point of our model is that, by choosing ex ante her level of activity, a limited liability firm also chooses to benefit or not to benefit ex post from what we call in the paper the 'ex post legal financial protection'. In other terms, if she chooses a level of activity that pushes her into bankruptcy after an incident, she will be liquidated but she will not have to pay more than the net value of her assets. If, on the contrary, she adopts a level of activity lower than the bankruptcy level, then her profit will always be positive, bankruptcy will never occur, all risk will be internalized by the firm and ex post legal financial protection will never be mobilized.

Several main results can be depicted here. We show that limited liability can be more incentive in terms of technological change than an unlimited liability rule when the level of technological damage depends on the level of activity. In particular, for large technological risks (high levels of damage in the case of an accident), high-capitalized firms may have more incentives for technological change under a limited liability.

Nevertheless, it must be noticed that the safest technology is not always the 'ideal' one for Society for it can push the firm to increase her level of activity and, therefore, it contributes to higher damage in the case of an accident. The possibility of manipulating the rate of tax with respect to the technological choice made by the firm permits it to mitigate this negative effect due to production in excess. This is still showed in the model of Section 3 which combines taxes with a limited liability rule.

The paper is organized as follows. Section 2 presents the basic hypotheses and the analysis on unlimited and limited liability. Section 3 focuses on the mix policy (taxes and rules). Section 4 concludes the paper.

\section{Liability rules and technological choice}

In this section, we analyze the technological choice made by a risk-neutral firm facing a technological risk and the level of activity she decides to adopt when she is subject first to unlimited liability, then to limited liability.

Consider a competitive economy with a representative risk-neutral firm selling an 
homogeneous product at a price $p$. The demand displays an infinite elasticity. The firm's activity induces a major risk of incident, which occurrence probability depends on the type of production technology she adopts. The firm has to choose between two technologies indexed by $i=1,2$. The first one is the technology initially adopted by the firm (default technology). It is less costly than the second one, but it also drives a higher incident probability. We denote it $\varphi_{i}$, with $\varphi_{i} \in[0,1]$ and $\varphi_{2}<\varphi_{1}$. We still denote $y_{i}$ the level of production chosen by the firm when she uses technology $i(i=1,2)$. The production cost for technology $i$ equals $Z_{i} y_{i}^{2}$ with $Z_{1}<Z_{2}$.

Let $d$ be the damage rate, that is the level of damage per unit of production borne by Society. Hence the total amount of damage $d y_{i}$ following an accident depends on the level of activity $y_{i}$ and, as a direct consequence, on the technological choice. The random variable defining the risk of accident for technology $i$ can be denoted as $\widetilde{D_{i}} \equiv$ $\left(1-\varphi_{i}, \varphi_{i} ; 0, d y_{i}\right)$.

Finally, assume that the firm finances her activity out of her equity $E$, with $E>0$.

Perfect information about the decisions of the firm takes place in this paper. The firm chooses the level of her activity and the technology she decides to keep (if $i=1$ ) or to adopt (if $i=2$ ). Thus the level of activity $y_{i}$ that maximizes her expected profit is a best response to a technology $i$.

\subsection{Unlimited versus limited liability}

Under an unlimited liability rule, a firm has to pay ex post for any damage caused by her activity, whatever her level of activity. In such a setting, ex post profits can be negative and the entire risk of incident is internalized. If the amount of damages is higher than the net value of the firm at the time of the accident, owners will have to pay out of their pocket. Formally, the firm's maximization program is:

$$
\max _{y_{i}, i} E\left(\widetilde{\Pi}_{i}\right)=p y_{i}-Z_{i} y_{i}^{2}-\varphi_{i} d y_{i}+E
$$


The private level of activity that is solution to (1), and denoted $y_{i}^{U L}$, satisfies:

$$
y_{i}^{U L}=\frac{p-\varphi_{i} d}{2 Z_{i}}, \quad i=1,2
$$

Knowing that the firm owns the technology 1, she decides to adopt the safer technology 2 if $E\left[\widetilde{\Pi_{2}}\right]-E\left[\widetilde{\Pi_{1}}\right]>0$. After computation and arrangement, we obtain the results in Proposition 1 hereafter.

Proposition 1 Under the unlimited liability rule, a risk-neutral firm chooses technology 2 if and only if :

$$
\frac{\left(p-\varphi_{1} d\right)^{2}}{Z_{1}}<\frac{\left(p-\varphi_{2} d\right)^{2}}{Z_{2}}
$$

Proof. See the appendix.

Inequality (3) is a standard difference of net marginal profits evaluated at optimum (the level of activity for each technology is the one that maximizes the expected profits). Technological change occurs if doing so is profitable.

Now let us consider the case in which the firm is protected by a limited liability rule. This means that she is, ex ante, responsible for all the damage caused by her activity but, ex post, she will not have to pay more than her net present value. Hence, if the damage is higher than the firm's net value, part of it will be borne by Society. Contrary to what is done in Beard (1990), Pitchford (1995) and Dionne and Spaeter (2003), who also consider limited liability, our approach endogenizes both the level of damage observed in the case of an accident and the possibility for the firm to effectively benefit, or not, from the financial limitation ex post. To well understand these features, we need to define the level of activity that pushes the firm into bankruptcy following an incident.

Lemma 1 Let $\widehat{y_{i}}$ be the production level that induces an ex post profit equal to zero when technology $i(i=1,2)$ is chosen and an accident occurs. We have:

$$
\widehat{y_{i}}=\frac{(p-d)+\sqrt{(p-d)^{2}+4 Z_{i} E}}{2 Z_{i}}
$$


Proof. By definition of $\widehat{y_{i}}$, the after accident profit writes:

$$
\begin{aligned}
p \widehat{y}_{i}-Z_{i}{\widehat{y_{i}}}^{2}-d \widehat{y_{i}}+E & =0 \\
-Z_{i}{\widehat{y_{i}}}^{2}+(p-d) \widehat{y}_{i}+E & =0
\end{aligned}
$$

Both roots are

$$
\widehat{y}_{i}=\frac{(p-d)+\sqrt{(p-d)^{2}+4 Z_{i} E}}{2 Z_{i}} \text { and } \widehat{y}_{i}=\frac{(p-d)-\sqrt{(p-d)^{2}+4 Z_{i} E}}{2 Z_{i}}
$$

The second root being always negative, Lemma 1 is proved.

In this framework, if a firm protected by the limited liability rule adopts a level of activity $y_{i}$ higher than $\widehat{y}_{i}$, she will benefit from the legal financial protection beyond her net value in the case of an accident: she will be declared as bankrupted and all her assets will be confiscated for compensation, but not more. Her final after accident profit will be zero whatever her activity level $y_{i}$ with $y_{i} \geq \widehat{y_{i}}$. If the firm chooses $y_{i}$ such that $y_{i}<\widehat{y_{i}}$, her profit will always be positive even in the case of an accident. The firm will always be able to pay for all the damages and she will not be in the situation of needing the legal protection offered by the limited liability rule. In this last situation, we will say that she has decided, by choosing a level of activity lower than the bankruptcy threshold $\widehat{y}_{i}$, not to be protected by ex post limited liability and to internalize all the risk driven by her activity.

As a direct consequence, the decision of taking or not taking advantage of the limited liability rule becomes endogenous to the model. This modifies the firm's maximization program compared to the preceding case (with unlimited liability). Now, it is composed of two steps. First, the firm acts as if she would be under an unlimited liability rule and she decides the optimal level of activity in this framework. Second, if the level of activity she chooses in the first step is higher than $\widehat{y}_{i}$, then she considers again her maximization program but in the limited liability frame. If the activity level is lower than $\widehat{y}_{i}$, the firm considers her decision process as taking place in an environment identical to the one that prevails with unlimited liability, with $y_{i} \in\left[0, \widehat{y}_{i}\right]$. Nevertheless, by doing so she will never be concerned by bankruptcy considerations even in the case of an accident, contrary to 
the unlimited liability case.

If the firm chooses $y_{i}>\widehat{y_{i}}$ (that means that $\left.E\left[\Pi\left(y_{i}\right)\right]>E\left[\Pi\left(y_{i}^{0}\right)\right], \forall y_{i}^{0} \leq \widehat{y_{i}}\right)$, she will benefit from ex post legal protection in the case of an accident. Her new program becomes:

$$
\max _{y_{i}}\left(1-\varphi_{i}\right)\left[p y_{i}-Z_{i} y_{i}^{2}+E\right]
$$

In the course of the paper, we will denote by $y_{i}^{L L+}$ the optimal level of activity when the firm chooses to benefit from ex post legal protection with technology $i$ (i.e. $\left.y_{i}^{L L+}>\widehat{y}_{i}\right)$ and by $y_{i}^{L L-}$ the optimal level of activity in the other limited liability case (i.e. $\left.y_{i}^{L L-}<\widehat{y}_{i}\right)$.

The optimal level of activity $y_{i}^{L L+}$, solution to Program (5), satisfies:

$$
y_{i}^{L L+}=\frac{p}{2 Z_{i}}
$$

On the contrary, if the firm chooses to produce less than $\widehat{y}_{i}$, her optimization program is similar to (1) and we obtain again

$$
y_{i}^{L L-}=\frac{p-\varphi_{i} d}{2 Z_{i}}
$$

The difference is that profits will never be negative since $y_{i}^{L L-}<\widehat{y}_{i}$, contrary to what can be obtained in the unlimited liability model.

Now, let us ask whether a technological change also induces a change in the willingness of the firm to adopt or to give up ex post legal protection.

Proposition 2 Consider a risk-neutral firm who benefits from ex post legal protection with technology $1\left(y_{1}^{L L+}>\widehat{y_{1}}\right)$ and who decides to adopt technology 2.

This firm turns to full risk internalization after technological change $\left(y_{2}^{L L-}<\widehat{y_{2}}\right)$ if and only if

$$
\varphi_{1}-a \leq \varphi_{2}<\varphi_{1}
$$

with $a=\frac{4 E}{d^{2}}\left(Z_{2}-Z_{1}\right)$.

In other (non technical) words, full internalization after technological change holds particularly for incremental innovation. 


\section{Proof. See Appendix.}

Incremental innovation means that technology 2 provides a small improvement in the safeness compared to technology 1: the difference between $\varphi_{1}$ and $\varphi_{2}$ should not be too high.

Another important point is that Condition (8) can never be satisfied for $E=0$. And the more $E$, the more the chance to observe full internalization of the risk after a technological change. As a direct consequence, high-capitalized firms seem to be more concerned by the result of Proposition 2. This is rather intuitive since high capitalized firms have more equity that can be confiscated for compensation following an incident.

In the following Proposition 3, we consider the opposite case to Proposition 2 and we stress the conditions that lead to the choice of ex post legal protection after technological change by the firm.

Proposition 3 Consider a risk-neutral firm that fully internalizes the risk of incident with technology $1\left(y_{1}^{L L-}<\widehat{y_{1}}\right)$ and that chooses to adopt technology 2.

(i) This firm turns to partial risk internalization $\left(y_{2}^{L L+}>\widehat{y_{2}}\right)$ if and only if

$$
\varphi_{2}<1-b<1-c \leq \varphi_{1}
$$

with $b=\frac{(p-d)^{2}+4 Z_{2} E}{d^{2}} \geq 0$ and $c=\frac{(p-d)^{2}+4 Z_{1} E}{d^{2}} \geq 0$.

(ii) In other (non technical) words, partial risk internalization after a technological change holds particularly for radical innovation.

\section{Proof. See Appendix.}

Radical innovation means that technology 2 provides a high improvement in the safeness compared to technology 1: $\varphi_{2}$ should be significantly lower than $\varphi_{1}$. Furthermore, still notice that Condition (9) is always satisfied for $E=0$. Thus small firms seem to have more incentives than high-capitalized ones to choose ex post legal protection after a technological change. It was also the case for incremental innovation since they move less often to full internalization (see Proposition 2).This can be explained by the fact 
that the level of activity that may push high-capitalized firms into bankprutcy after an accident is higher than for small firms knowing that the equity $E$ of the former is higher.

Radical innovation can induce more future uncertainty for the firm. Deciding to be financially protected ex post in the case of an incident can be considered as a way to deal with this increasing uncertainty. Nevertheless, this uncertainty is not explicitely captured by our model. Moreover, the firm is risk neutral. Here the optimality of ex post financial protection is a direct consequence of the increase of the level of activity: the good becoming more profitable, the firms decides to increase her production such that the total damage, in the case of an incident, leads to bankruptcy.

The incentives to benefit or not from ex post legal protection being identified, we still have to analyze the conditions under which technological change really occurs under limited liability. Since the maximization program is non differentiable in $\widehat{y_{i}}$, we have to consider the successive four following cases:

a) Technology 1 and full internalization $=>$ technology 2 and full internalization.

b) Technology 1 and partial internalization $=>$ technology 2 and full internalization.

c) Technology 1 and partial internalization $=>$ technology 2 and partial internalization.

d) Technology 1 and full internalization $=>$ technology 2 and partial internalization.

In each case we must compare the adequate expected profits. Nevertheless, being interested by arguments that could help a decisionmaker in defining incentives for both technological change and full internalization, we focus essentially on cases a) and b). Cases c) and d) are proposed in the Annex.

For the sake of clarity, we keep referring to full internalization when talking about limited liability without ex post protection $\left(y_{i}^{L L-}<\widehat{y}_{i}\right)$ and to partial internalization when the firm chooses ex post legal protection $\left(y_{i}^{L L+} \geq \widehat{y}_{i}\right)$. 
Proposition 4 Assume that a limited liability rule holds.

a) A firm having adopted full risk internalization with technology 1 turns to technology 2 while keeping full risk internalization if:

$$
\frac{\left(p-\varphi_{1} d\right)^{2}}{Z_{1}}<\frac{\left(p-\varphi_{2} d\right)^{2}}{Z_{2}}
$$

or

$$
0<\left(p-\varphi_{2} d\right) y_{2}^{L L-}-\left(p-\varphi_{1} d\right) y_{1}^{L L-}
$$

b) A firm having adopted partial risk internalization with technology 1 turns to technology 2 and full risk internalization if:

$$
p\left(1-\varphi_{1}\right) y_{1}^{L L+}-\left(p-\varphi_{2} d\right) y_{2}^{L L-}<2 \varphi_{1} E
$$

Proof. See Appendix.

Each inequality in Proposition 4 can be interpreted in terms of expected marginal cost and marginal benefit following a technological change.

This ends the separate analysis of both liability rules. We must know compare them in terms of incentives to technological change.

\subsection{More incentives with a limited liability rule}

In this section, we highlight the conditions under which a firm has more incentives to move from technology 1 to technology 2 when she is protected by limited liability.

Recall that a firm who decides ex ante to give up the ex post legal protection (by choosing $y_{i}^{L L-}<\widehat{y}_{i}$ ) has a maximization program close to the one obtained in an unlimited liability rule. We do not consider the case here. We focus on the more striking case relative to the comparison between unlimited liability and limited liability with legal protection. 
Proposition 5 Denote as 'LL rule' the limited liability rule with ex post legal protection and as 'UL rule' the unlimited liability rule.

(i) $2 d-p>0$ is a necessary condition for a firm to choose a LL rule.

(ii) The firm under a LL rule will move more frequently from technology 1 to technology 2 than with a UL rule iff:

$$
\left(\varphi_{1}-\varphi_{2}\right) 4 E>d^{2}\left(\frac{\varphi_{2}^{2}}{Z_{2}}-\frac{\varphi_{1}^{2}}{Z_{1}}\right)-p(2 d-p)\left(\frac{\varphi_{2}}{Z_{2}}-\frac{\varphi_{1}}{Z_{1}}\right)
$$

(iii) Point (ii) is all the more satisfied since E is high.

Proof. See the appendix.

Point (i) implies that limited liability with ex post legal protection becomes attractive for firms only for some large risks: $d$ must be sufficiently large compared to $p .{ }^{4}$

Point (ii) provides conditions under which a limited liability rule (with ex post legal protection) is more incentive in terms of technological change than the unlimited liability rule. This result is interesting since it implies that firms may prefer a technology that costs more with certainty, while limited liability permits them to be financially (partially) protected in the case of a huge incident. Recall that when changing their technology, they also change their level of activity and, as a direct consequence of our model, all the parameters of their profits (gross returns, total production costs and expected damages). Here technological change leads simultaneously to risk mitigation and change in the production supply.

Finally, limited liability seems to be a good way to simultaneously incite firms to go on some markets (to produce) and to choose safe technologies. Here, risk mitigation and limited liability are not opposed, contrary to what is often showed in the literature. ${ }^{5}$

\footnotetext{
${ }^{4}$ Nevertheless, notice that if $p$ is very small the damage rate does not need to be high. Actually, what is important is the total level of damage $d y_{i}$. And if the firm sells a good with a small price $p$, she will, generally, also produce a large quantity $y_{i}$ of this good in order to make profitable the purchase of the technology. Thus, the technological risks that we consider are large because $d$ or $y_{i}$ are high.

${ }^{5}$ Recall that Shavell (1986), Beard (1990), Pitchford (1995), Boyer and Laffont (1997), and Dionne and Spaeter (2003) show, among other points, that limited liability of firms lead to less risk internalization and less prevention. These results have been obtained in models with levels of damage that do not depend on the level of activity of the firm. Moreover, less risk internalization is also the main argument used by some jurists to put in doubt the efficiency of limited liability(see, e.g., Hansmann and Kraakman, 1991).
} 
Point (iii) provides an interesting comparative static result for decision-making. High capitalized firms will move more frequently toward a safer technology under a limited liability rule with ex post legal protection. Hence Point (iii) could also be an argument in favor of a differentiation in the liability rules applied in the industries ${ }^{6}$, depending on the size of the firms and/or the type of technological innovation (incremental or radical) that is in force when comparing technology 1 and technology 2 (see Propositions 2 and $3)$.

\section{A '(limited liability) rule and tax' policy}

In this section, we focus on a mix policy, that is a policy that allows for the simultaneous use of a limited liability rule and some more standard incentive tools, such as taxes. The aim of such a mix policy is to enlarge the set of parameters for which a given risk-neutral firm has an interest in switching from technology 1 to technology 2, without having to use the so discussed unlimited liability rule.

Let us assume that the production is taxed. The technology chosen by the firm is observable by the regulator so that the tax rate can be differentiated with respect to the technology. We denote it as $t_{i}, i=1,2$.

Such an hypothesis calls for an explanation. It can be disturbing to assume that production, rather than marginal cost, is taxed ${ }^{7}$. But recall that the level of activity $y_{i}$ chosen by the firm affects the level of risk borne by Society. What will be important is the ability of the regulator to fix the level of tax rate with respect to the technology he wants to be adopted by the firm. Recall that the firm can also mitigate the risk for a given level of activity by choosing the safer technology. Furthermore, the tax rate can be negative, so that subsidies might also exist. Thus a firm who would like to escape from paying too much tax can either reduce her production or move to the less taxed

\footnotetext{
${ }^{6}$ This point could be an argument to apply limited liability to sectors in which it is usual to observe some widely held firms, as advocated by Halpern, Trebilcock and Turnbull (1980).

${ }^{7}$ Actually, such type of taxation is more usual in environmental policies, the aim of which being clearly to reduce emission and to give some incentives to change the pollutant technologies. Concerning heating gases for instance, several countries (Switzerland, Sweden, Norway, Denmark, Finland, Germany, England; while France tried in 2009, but failed, to implement a "carbon tax") have already adopted taxes based on the production of some specific sectors or on the consumption of some specific goods.
} 
technology. She can also adopt simultaneously both strategies.

Under an unlimited liability rule, the new maximization program becomes:

$$
\max _{y_{i}, i} E\left(\widetilde{\Pi_{i}}\right)=p y_{i}-t_{i} y_{i}-Z_{i} y_{i}^{2}-\varphi_{i} d y_{i}+E
$$

or

$$
\max _{y_{i}, i} E\left(\widetilde{\Pi_{i}}\right)=p_{i} y_{i}-Z_{i} y_{i}^{2}-\varphi_{i} d y_{i}+E
$$

with $p_{i}=p-t_{i}$. Introducing such a tax is such like differentiating prices with respect to the chosen technology. Nevertheless, in this setting goods keep continuing to be sold at price $p$ : No aspect of consumers' willingness to pay for safe products is considered. This is out of the scope of this paper.

The private level of activity solution to (14), and denoted $y_{i}^{t U L}$, satisfies:

$$
y_{i}^{t U L}=\frac{p-t_{i}-\varphi_{i} d}{2 Z_{i}}, \quad i=1,2
$$

And we obtain the following result. "Technology $i$ becomes relatively more attractive" means that there exists a larger set of parameters' values that leads to the choice of technology $i$ at optimum.

\section{Proposition 6}

(i) Under an unlimited liability rule combined with a tax on production, a risk-neutral firm chooses technology 2 if and only if :

$$
\frac{\left(p-t_{1}-\varphi_{1} d\right)^{2}}{Z_{1}}<\frac{\left(p-t_{2}-\varphi_{2} d\right)^{2}}{Z_{2}}
$$

(ii) Technology $i$ becomes relatively more attractive following an increase in the tax rate $t_{j}, j \neq i, i=1,2, j=1,2$.

(iii) If $y_{i}^{t U L}>y_{j}^{t U L}$, then technology $i$ becomes relatively more attractive following an identical and simultaneous decrease in both tax rates $t_{1}$ and $t_{2}$.

Proof. See Appendix. 
Since both technologies are substitutable, the regulator has several means for influencing the adoption of technology 2 . Indeed he can increase $t_{1}$, decrease $t_{2}$ or even decrease both tax rates in some contexts. All these strategies lead to a higher attractiveness of technology 2 , but the revenue of the tax agency is different.

Now, let us turn to the limited liability rule. Other things being equal, introducing taxes on production lessens the level of activity that pushes the firm into bankruptcy following an accident. Thus it deteriorates the financial condition of the firm. Nevertheless, the firm can react to taxation by modifying her level of activity. And, as a direct consequence, the total amount of damage in the case of an accident is also lowered.

Such as in Lemma 1, the level $\widehat{y_{i}^{t}}$ of production that induces an ex post profit equal to zero when technology $i(i=1,2)$ is chosen and an accident occurs is defined as satisfying $\left(p-t_{i}\right) \widehat{y_{i}^{t}}-Z_{i}{\widehat{y_{i}^{t}}}^{2}-d \widehat{y_{i}^{t}}+E=0$. Still here, the firm can decide to benefit or not to benefit from the ex post legal protection by choosing ex ante an adequate level of activity.

Assume that the firm chooses $y_{i}^{t}>\widehat{y_{i}^{t}}$. Her new program becomes $\operatorname{Max}_{y_{i}^{t}, i} \quad\left(1-\varphi_{i}\right)\left(\left(p-t_{i}\right) y_{i}^{t}-Z_{i} y_{i}^{t 2}+E\right)$. And the optimal level of activity denoted as $y_{i}^{t L L+}$ satisfies:

$$
y_{i}^{t L L+}=\frac{p-t_{i}}{2 Z_{i}}
$$

On the contrary, if the firm chooses to produce less than $\widehat{y_{i}^{t}}$, her optimization program is similar to (14), with the difference that it is never negative under the limited liability rule. We have :

$$
y_{i}^{t L L-}=\frac{p-t_{i}-\varphi_{i} d}{2 Z_{i}}, \quad i=1,2
$$

Proposition 7 Assume that a limited liability rule holds.

(i) A risk-neutral firm chooses to benefit from the legal protection in the case of an accident if and only if:

$$
\varphi_{i}<1-\frac{\left(p-t_{i}-d\right)^{2}+4 Z_{i} E}{d^{2}}
$$

(ii) For a given technology $i=1,2$, a decrease in the tax rate $t_{i}$ decreases the attractivity of ex post legal protection for the firm.

Proof. See Appendix. 
Less tax leads to better risk internalization under a limited liability rule when technological change is not considered. Hence, taxation can improve risk internalization despite the limitation of the maximum amount of loss suffered by a limited liability firm in the case of an accident.

In Proposition 8 hereafter we consider some technological change. Since our aim is to show that limited liability does not always lead to the worst risk internalization and to the poorest incentives to move to safer technologies, we focus essentially on technological change followed by full internalization.

Proposition 8 Assume that a limited liability rule holds and that a unit tax, depending on the chosen technology, is applied to each unit of production.

(i) A firm having adopted full risk internalization with technology 1 turns more frequently to technology 2 with full risk internalization than in a system without tax if $t_{1}>t_{2}$.

(ii) A firm having adopted partial risk internalization with technology 1 turns more frequently to technology 2 and full risk internalization than in a liability system without tax if

$$
\frac{t_{1}\left(2 p-t_{1}\right)\left(1-\varphi_{1}\right)}{t_{2}\left(2\left(p-\varphi_{2} d\right)-t_{2}\right)}>\frac{Z_{1}}{Z_{2}}
$$

This condition is all the more satisfied since $t_{1}$ is high for a given $t_{2}$ ( $t_{2}$ is low for a given $\left.t_{1}\right)$.

Proof. See Appendix.

In situations where applying unlimited liability would be too costly for Society (in terms of innovative projects that would not been concretized or of information seeking for instance), limited liability can be a good rule if it is combined with taxes depending on the technological choice made by the firms.

\section{Conclusion}

In this paper, we have considered a firm the activity of which drives a technological, large-scale risk for Society. The main objective of this paper was to show that a limited 
liability rule can also be technical change incentive when compared to an unlimited liability rule. The introduction of taxes in the last section permitted it to reinforce this result under some conditions.

The risk of technological incident is multiplicative in the sense that the magnitude of the potential damage increases with the level of production. Two technologies were available: the default technology displays a higher probability of accident than the safer one, but also a lower marginal cost of production. By considering the relationship between the technological risk, the technical choice and the level of activity, one originality of our contribution was to allow the firm to choose to potentially benefit or not from the legal financial protection offered by a limited liability rule when a damage occurs. More explicitely, she could choose a level of activity such that she was never bankrupted in the case of a damage. In this way, she fully internalizes the risk despite the fact that she could benefit from limited liability.

One general result that we obtained is that a limited liability rule does not always lead to less risk internalization. Indeed, firms can choose a level of activity such that the induced amount of damage is not too high in the case of an incident. Beside, we have also showed that R\&D, which would lead to safer technologies by decreasing the rate of damage, can induce less risk internalization when the level of activity is simultanously increased.

We have also showed that a limited liability firm who decides to invest in the safest technology also adopts full risk internalization if this new technology differs from the default one thanks to an incremental innovation, while she prefers to be ex post protected by legal protection if radical innovation has taken place. This result seems counterintuitive. Nevertheless the conditions required to observe some full risk internalization concern high-capitalized firms. Moreover, innovation permits it to have access to safer technologies and, in our model, this impacts directly the optimal level of activity of the firm. Hence, a radical innovation is not necessarily socially desirable for it can increase the level of activity chosen by the firm and then increase the level of damage in the case of an incident. This highlights the trade-off to be made in some specific settings by the regulator between ex ante mitigation (less chance to observe an incident) and ex post 
mitigation (less damage if an incident occurs).

In the last section of the paper, we tried to enlarge the set of the conditions that lead to technological change by giving the regulator an additional regulatory tool, namely taxation. The tax rate is applied to production (recall that it affects the level of damage), and it can be differentiated with respect to the chosen technology. In this setting, it was showed that technological change AND full risk internalization is likely to be observed in a system where production obtained with the default technology is taxed, while the safest technology is exempted from tax payment.

All these results permit us to conclude first that limited liability can initiate technological change without always deteriorating risk internalization by the firm. Second, liability rules combined with more classical regulatory tools like taxation give several interesting and powerful dimensions to the regulator's policy. Lastly, these dimensions should be used in particular to differentiate the policies thanks to the type of sector that is considered (high-capitalized firms, small or medium firms) and with respect to the innovation that is in force (incremental or radical). The dangerousness of the activity should also be an important feature of the regulation as already argued by Shavell (1986, 2004). Indeed limited liability may not be preferred if the potential damage is huge even if technological change seems to be more likely to be observed with legal protection.

Our model is based on simple assumptions and its scope could (and should) be extended. The first extension could be to study the impact of the existence of a not yet finalized technology, in the sense that additionnal R\&D is needed to properly assess its risk. This could permit us to study the behaviors of firms facing rules that compel them to do additionnal R\&D or tests before using a new technology. Another interesting extension of this work could be to consider an endogeneous level of capital by allowing firms to borrow funds from a bank, and thus studying their behavior concerning risk management (choice of the technology and the activity level) when they are endowed with external funds (such as debt for instance) and equity. 


\section{Appendix}

\section{Proof of Proposition 1}

We have to compute $E\left(\widetilde{\Pi_{2}}\right)-E\left(\widetilde{\Pi_{1}}\right)>0$ at optimum:

$$
\begin{aligned}
& p y_{2}^{U L}-Z_{2}\left(y_{2}^{U L}\right)^{2}-\varphi_{2} d y_{2}^{U L}+E>p y_{1}^{U L}-Z_{1}\left(y_{1}^{U L}\right)^{2}-\varphi_{1} d y_{1}^{U L}+E \\
& \Leftrightarrow p\left(y_{2}^{U L}-y_{1}^{U L}\right)-\left(Z_{2}\left(y_{2}^{U L}\right)^{2}-Z_{1}\left(y_{1}^{U L}\right)^{2}\right)-d\left(\varphi_{2} y_{2}^{U L}-\varphi_{1} y_{1}^{U L}\right)>0
\end{aligned}
$$

Using (2), we must have:

$$
\begin{gathered}
p\left(\frac{p-\varphi_{2} d}{2 Z_{2}}-\frac{p-\varphi_{1} d}{2 Z_{1}}\right)-\left(\frac{\left(p-\varphi_{2} d\right)^{2}}{4 Z_{2}}-\frac{\left(p-\varphi_{1} d\right)^{2}}{4 Z_{1}}\right)-d\left(\frac{\varphi_{2}\left(p-\varphi_{2} d\right)}{2 Z_{2}}-\frac{\varphi_{1}\left(p-\varphi_{1} d\right)}{2 Z_{1}}\right)>0 \\
\Leftrightarrow p\left[Z_{1}\left(p-\varphi_{2} d\right)-Z_{2}\left(p-\varphi_{1} d\right)\right]-\frac{1}{2}\left[Z_{1}\left(p-\varphi_{2} d\right)^{2}-Z_{2}\left(p-\varphi_{1} d\right)^{2}\right] \\
-d\left[Z_{1} \varphi_{2}\left(p-\varphi_{2} d\right)-Z_{2} \varphi_{1}\left(p-\varphi_{1} d\right)\right]>0 \\
\Leftrightarrow Z_{1}\left(p-\varphi_{2} d\right)\left[p-\frac{1}{2}\left(p-\varphi_{2} d\right)-d \varphi_{2}\right]-Z_{2}\left(p-\varphi_{1} d\right)\left[p-\frac{1}{2}\left(p-\varphi_{1} d\right)-d \varphi_{1}\right]>0 \\
\Leftrightarrow Z_{1}\left(p-\varphi_{2} d\right)\left[\frac{1}{2}\left(p-\varphi_{2} d\right)\right]-Z_{2}\left(p-\varphi_{1} d\right)\left[\frac{1}{2}\left(p-\varphi_{1} d\right)\right]>0 \\
\Leftrightarrow Z_{1}\left(p-\varphi_{2} d\right)^{2}>Z_{2}\left(p-\varphi_{1} d\right)^{2} \\
\Leftrightarrow \frac{\left(p-\varphi_{1} d\right)^{2}}{Z_{1}}<\frac{\left(p-\varphi_{2} d\right)^{2}}{Z_{2}}
\end{gathered}
$$

Proposition 1 is demonstrated.

\section{Proof of Proposition 2.}

First, let us show that a risk-neutral firm chooses, under limited liability and with technology $i$, to benefit from full internalization in the case of an accident if and only if:

$$
\varphi_{i} \geq 1-\frac{(p-d)^{2}+4 Z_{i} E}{d^{2}}
$$


with $\frac{(p-d)^{2}+4 Z_{i} E}{d^{2}}<1$. This is the case if $E\left[\pi\left(y_{i}^{L L-}\right)\right] \geq E\left[\pi\left(y_{i}^{L L+}\right)\right]$ :

$$
\begin{aligned}
p y_{i}^{L L-}-Z_{i}\left(y_{i}^{L L-}\right)^{2}-\varphi_{i} d y_{i}^{L L-}+E & \geq\left(1-\varphi_{i}\right)\left(p y_{i}^{L L+}-Z_{i}\left(y_{i}^{L L+}\right)^{2}+E\right) \\
\left(p-Z_{i} y_{i}^{L L-}-\varphi_{i} d\right) y_{i}^{L L-}+E & \geq\left(1-\varphi_{i}\right)\left(\left(p-Z_{i} y_{i}^{L L+}\right) y_{i}^{L L+}+E\right) \\
\frac{\left(p-\varphi_{i} d\right)}{2} \frac{\left(p-\varphi_{i} d\right)}{2 Z_{i}}+E & \geq\left(1-\varphi_{i}\right)\left(\frac{p}{2} \frac{p}{2 Z_{i}}+E\right) \\
\left(p-\varphi_{i} d\right)^{2}-\left(1-\varphi_{i}\right) p^{2}+4 Z_{i} \varphi_{i} E & \geq 0 \\
\varphi_{i}\left(-2 p d+\varphi_{i} d^{2}+4 Z_{i} E+p^{2}\right) & \geq 0 \\
-2 p d+\varphi_{i} d^{2}+4 Z_{i} E+p^{2} & \geq 0 \\
\varphi_{i} & \geq 1-\frac{(p-d)^{2}+4 Z_{i} E}{d^{2}}
\end{aligned}
$$

It is easy to check that $\frac{(p-d)^{2}+4 Z_{i} E}{d^{2}}<1$ when the optimum for the firm is $y_{i}^{L L+}>\widehat{y_{i}}$. Rearranging the terms in (21) leads to:

$$
\begin{aligned}
& \varphi_{2} \geq 1-\frac{(p-d)^{2}+4 Z_{2} E}{d^{2}}+\frac{4 E}{d^{2}}\left(Z_{1}-Z_{1}\right) \\
& \varphi_{2} \geq 1-\frac{(p-d)^{2}+4 Z_{1} E}{d^{2}}-\frac{4 E}{d^{2}}\left(Z_{2}-Z_{1}\right) \\
& \varphi_{2} \geq \varphi_{1}-\frac{4 E}{d^{2}}\left(Z_{2}-Z_{1}\right)
\end{aligned}
$$

Knowing that, by definition, $\varphi_{2}<\varphi_{1}$, Proposition 2 is demonstrated.

\section{Proof of Proposition 3.}

$>$ From (21), the firm adopts full risk internalization with technology $1\left(y_{1}^{L L-}<\widehat{y_{1}}\right)$ if and only if:

$$
\varphi_{1} \geq 1-\frac{(p-d)^{2}+4 Z_{1} E}{d^{2}}
$$

and she turns to partial risk internalization after technological change iff

$$
\varphi_{2}<1-\frac{(p-d)^{2}+4 Z_{2} E}{d^{2}}
$$

Having $Z_{1}<Z_{2}$ by definition, we also have $b=\frac{(p-d)^{2}+4 Z_{2} E}{d^{2}}>\frac{(p-d)^{2}+4 Z_{1} E}{d^{2}}=c \geq 0$. As a direct consequence of Conditions (22) and (23), we have that $\varphi_{2}<1-b<1-c \leq \varphi_{1}$. Point (ii) is immediate. Proposition 3 is demonstrated. 


\section{Proof of Proposition 4.}

For case a), we have to compute $E\left[\pi\left(y_{1}^{L L-}\right)\right]<E\left[\pi\left(y_{2}^{L L-}\right)\right]$ which is equivalent to the unlimited case presented in Proposition 1 and demonstrated above (see Equ. (20)). For case b), we must compute $E\left[\pi\left(y_{2}^{L L-}\right)\right]-E\left[\pi\left(y_{1}^{L L+}\right)\right]>0$, that is:

$$
\begin{aligned}
\left(p-\varphi_{2} d\right) y_{2}^{L L-}-Z_{2}\left(y_{2}^{L L-}\right)^{2}+E-\left(1-\varphi_{1}\right)\left(p y_{1}^{L L+}-Z_{1}\left(y_{1}^{L L+}\right)^{2}+E\right) & >0 \\
\left(p-\varphi_{2} d\right) y_{2}^{L L-}-p\left(1-\varphi_{1}\right) y_{1}^{L L+}-\frac{\left(p-\varphi_{2} d\right)^{2}}{4 Z_{2}}+\frac{\left(1-\varphi_{1}\right) p^{2}}{4 Z_{1}}+\varphi_{1} E & >0 \\
p\left(1-\varphi_{1}\right) y_{1}^{L L+}-\left(p-\varphi_{2} d\right) y_{2}^{L L-}+\frac{1}{2}\left(\left(p-\varphi_{2} d\right) y_{2}^{L L-}-p\left(1-\varphi_{1}\right) y_{1}^{L L+}\right) & <\varphi_{1} E \\
p\left(1-\varphi_{1}\right) y_{1}^{L L+}-\left(p-\varphi_{2} d\right) y_{2}^{L L-} & <2 \varphi_{1} E
\end{aligned}
$$

Proposition 4 is demonstrated.

\section{Proof of Proposition 5.}

$>$ From (21), we can also deduce that a firm under a limited liability rule chooses to benefit from the ex post legal protection if:

$$
\varphi_{i}<1-\frac{(p-d)^{2}+4 Z_{i} E}{d^{2}}
$$

So we must have:

$$
\begin{aligned}
& \frac{(p-d)^{2}+4 Z_{i} E}{d^{2}}<1 \\
\Leftrightarrow & p^{2}-2 p d+4 Z_{i} E<0 \\
\Leftrightarrow & p(p-2 d)+4 Z_{i} E<0
\end{aligned}
$$

This last inequality can only be satisfied if $p-2 d<0$, which is Point (i).

Under unlimited liability, the firm adopts technology 2 iff (Equ. (3)):

$$
\begin{gathered}
\frac{Z_{2} \cdot\left(p-\varphi_{1} d\right)^{2}-Z_{1} \cdot\left(p-\varphi_{2} d\right)^{2}}{Z_{1} \cdot Z_{2}}<0 \\
\Leftrightarrow p^{2} \cdot\left(Z_{2}-Z_{1}\right)-2 d p\left(Z_{2} \cdot \varphi_{1}-Z_{1} \cdot \varphi_{2}\right)<d^{2}\left(\varphi_{2}^{2} Z_{1}-\varphi_{1}^{2} Z_{2}\right)
\end{gathered}
$$

By using the notation $A=p \cdot\left(Z_{2} \cdot\left(1-\varphi_{1}\right)-Z_{1} \cdot\left(1-\varphi_{2}\right)\right)$ and $d=p-\gamma$ with $\gamma \in \mathbb{R}$, this 
inequality becomes:

$$
\begin{aligned}
& A+(p-2 \gamma)\left(Z_{1} \varphi_{2}-Z_{2} \varphi_{1}\right)<\frac{d^{2}\left(\varphi_{2}^{2} Z_{1}-\varphi_{1}^{2} Z_{2}\right)}{p} \\
\Leftrightarrow & A<\frac{d^{2}\left(\varphi_{2}^{2} Z_{1}-\varphi_{1}^{2} Z_{2}\right)}{p}+(p-2 d)\left(Z_{1} \varphi_{2}-Z_{2} \varphi_{1}\right)
\end{aligned}
$$

Under limited liability, technological change occurs iff (see Equ. (27) in the Annex, case c)):

$$
\begin{gathered}
\varphi_{1}-\varphi_{2}>\frac{1}{E} \cdot\left(\left(1-\varphi_{1}\right) \cdot \frac{p^{2}}{4 Z_{1}}-\left(1-\varphi_{2}\right) \cdot \frac{p^{2}}{4 Z_{2}}\right) \\
\Leftrightarrow p^{2} \cdot\left(Z_{2}-Z_{1}\right)-p^{2}\left(Z_{2} \cdot \varphi_{1}-Z_{1} \cdot \varphi_{2}\right)<4 E \cdot\left(\varphi_{1}-\varphi_{2}\right) \cdot Z_{1} Z_{2}
\end{gathered}
$$

By using the same notation $A=p \cdot\left(Z_{2} \cdot\left(1-\varphi_{1}\right)-Z_{1} \cdot\left(1-\varphi_{2}\right)\right)$, this inequality becomes:

$$
A<\frac{\left(\varphi_{1}-\varphi_{2}\right) 4 E Z_{1} Z_{2}}{p}
$$

Finally, a LL rule with ex post legal protection gives more incentives to the firm to adopt technology 2 than a UL rule iff:

$$
\begin{gathered}
\frac{\left(\varphi_{1}-\varphi_{2}\right) 4 E Z_{1} Z_{2}}{p}-\left[\frac{d^{2}\left(\varphi_{2}^{2} Z_{1}-\varphi_{1}^{2} Z_{2}\right)}{p}+(p-2 d)\left(Z_{1} \varphi_{2}-Z_{2} \varphi_{1}\right)\right]>0 \\
\Leftrightarrow\left(\varphi_{1}-\varphi_{2}\right) 4 E>d^{2}\left(\frac{\varphi_{2}^{2}}{Z_{2}}-\frac{\varphi_{1}^{2}}{Z_{1}}\right)-p(2 d-p)\left(\frac{\varphi_{2}}{Z_{2}}-\frac{\varphi_{1}}{Z_{1}}\right)
\end{gathered}
$$

This is Point (ii). Point (iii) is immediate when looking at this last inequality for $E$ appears only in the left-hand-side term. Proposition 5 is demonstrated.

\section{Proof of Proposition 6.}

By replacing $p$ by $p_{i}=p-t_{i}$, the proof of point (i) is similar to the proof of Proposition 1. Point (ii) comes directly from inequality (16). For point (iii), consider Inequality (16) 
and the derivative fo both terms with respect to $t_{i}, i=1,2$ :

$$
\begin{aligned}
& \frac{\partial}{\partial t_{1}}\left(\frac{\left(p-t_{1}-\varphi_{1} d\right)^{2}}{Z_{1}}\right)-\frac{\partial}{\partial t_{2}}\left(\frac{\left(p-t_{2}-\varphi_{2} d\right)^{2}}{Z_{2}}\right) \\
= & -2 \frac{\left(p_{1}-\varphi_{1} d\right)}{Z_{1}}+2 \frac{\left(p_{2}-\varphi_{2} d\right)}{Z_{2}} \\
= & 4\left(\frac{\left(p_{2}-\varphi_{2} d\right)}{2 Z_{2}}-\frac{\left(p_{1}-\varphi_{1} d\right)}{2 Z_{1}}\right) \\
= & 4\left(y_{2}^{t U L}-y_{1}^{t U L}\right)
\end{aligned}
$$

This derivative is positive (negative) if $y_{2}^{t U L}-y_{1}^{t U L}$ is positive (negative). Point (iii) follows. Proposition 6 is demonstrated.

\section{Proof of Proposition 7.}

With $p_{i}=p-t_{i}$, we have $E\left[\pi\left(y_{i}^{t L L-}\right)\right]<E\left[\pi\left(y_{i}^{t L L+}\right)\right]$ if

$$
\begin{aligned}
p_{i} y_{i}^{t L L-}-Z_{i}\left(y_{i}^{t L L-}\right)^{2}-\varphi_{i} d y_{i}^{t L L-}+E & <\left(1-\varphi_{i}\right)\left(p_{i} y_{i}^{t L L+}-Z_{i}\left(y_{i}^{t L L+}\right)^{2}+E\right) \\
\left(p_{i}-Z_{i} y_{i}^{t L L-}-\varphi_{i} d\right) y_{i}^{t L L-}+E & <\left(1-\varphi_{i}\right)\left(\left(p_{i}-Z_{i} y_{i}^{t L L+}\right) y_{i}^{t L L+}+E\right) \\
\frac{\left(p_{i}-\varphi_{i} d\right)}{2} \frac{\left(p_{i}-\varphi_{i} d\right)}{2 Z_{i}}+E & <\left(1-\varphi_{i}\right)\left(\frac{p_{i}}{2} \frac{p_{i}}{2 Z_{i}}+E\right) \\
\left(p_{i}-\varphi_{i} d\right)^{2}-\left(1-\varphi_{i}\right) p_{i}^{2}+4 Z_{i} \varphi_{i} E & <0 \\
\varphi_{i}\left(-2 p_{i} d+\varphi_{i} d^{2}+4 Z_{i} E+p_{i}^{2}\right) & <0 \\
-2 p_{i} d+\varphi_{i} d^{2}+4 Z_{i} E+p_{i}^{2} & <0 \\
\varphi_{i} & <1-\frac{\left(p_{i}-d\right)^{2}+4 Z_{i} E}{d^{2}}
\end{aligned}
$$

It is easy to check that $\frac{\left(p_{i}-d\right)^{2}+4 Z_{i} E}{d^{2}}<1$ when the optimum is $y_{i}^{t L L+}>\widehat{y_{i}^{t}}$. This is Point (i). Point (ii) is immediate from (19). Proposition 6 is demonstrated.

\section{Proof of Proposition 8.}

Point (i) derives from the comparison of (3) and (16). Concerning point (ii), recall that a firm having adopted partial risk internalization with technology 1 turns to technology 2 and full risk internalization if $p\left(1-\varphi_{1}\right) y_{1}^{L L+}-\left(p-\varphi_{2} d\right) y_{2}^{L L-}<2 \varphi_{1} E$ (Condition (12)). By applying it to a limited liability system with tax ( $p$ is replaced by $p_{i}$ for 
technology $i$ ) we obtain the following condition:

$$
p_{1}\left(1-\varphi_{1}\right) y_{1}^{t L L+}-\left(p_{2}-\varphi_{2} d\right) y_{2}^{t L L-}<2 \varphi_{1} E
$$

Replace $y_{2}^{t L L-}$ and $y_{1}^{t L L+}$ by their optimal value (given by (18) and (17)) in this last inequality and $y_{2}^{L L-}$ and $y_{1}^{L L+}$ by their optimal value (given by (7) and (6)) in (12). We obtain

$$
p^{2}\left(1-\varphi_{1}\right) Z_{2}-\left(p-\varphi_{2} d\right)^{2} Z_{1}<4 \varphi_{1} Z_{1} Z_{2} E
$$

and

$$
p_{1}^{2}\left(1-\varphi_{1}\right) Z_{2}-\left(p_{2}-\varphi_{2} d\right)^{2} Z_{1}<4 \varphi_{1} Z_{1} Z_{2} E
$$

Both right-hand-side terms being equal, we obtain the result of point (ii) if

$$
p_{1}^{2}\left(1-\varphi_{1}\right) Z_{2}-\left(p_{2}-\varphi_{2} d\right)^{2} Z_{1}>p^{2}\left(1-\varphi_{1}\right) Z_{2}-\left(p-\varphi_{2} d\right)^{2} Z_{1}
$$

$\Leftrightarrow$

$$
\begin{aligned}
\left(p_{1}^{2}-p^{2}\right)\left(1-\varphi_{1}\right) Z_{2}-\left(\left(p_{2}-\varphi_{2} d\right)^{2}-\left(p-\varphi_{2} d\right)^{2}\right) Z_{1} & >0 \\
\left(p_{1}^{2}-p^{2}\right)\left(1-\varphi_{1}\right) Z_{2}-\left(\left(p_{2}-\varphi_{2} d\right)-\left(p-\varphi_{2} d\right)\right)\left(\left(p_{2}-\varphi_{2} d\right)+\left(p-\varphi_{2} d\right)\right) Z_{1} & >0 \\
\left(p_{1}^{2}-p^{2}\right)\left(1-\varphi_{1}\right) Z_{2}-\left(p_{2}+p-2 \varphi_{2} d\right)\left(p_{2}-p\right) Z_{1} & >0
\end{aligned}
$$

Recall that $p_{1}=p-t_{1}$ and $p_{2}=p-t_{2}$. Thus:

$$
\begin{aligned}
\left(\left(p-t_{1}\right)^{2}-p^{2}\right)\left(1-\varphi_{1}\right) Z_{2}+\left(2 p-t_{2}-2 \varphi_{2} d\right) t_{2} Z_{1} & >0 \\
t_{1}\left(t_{1}-2 p\right)\left(1-\varphi_{1}\right) Z_{2}+t_{2}\left(2\left(p-\varphi_{2} d\right)-t_{2}\right) Z_{1} & >0 \\
\frac{t_{1}\left(t_{1}-2 p\right)\left(1-\varphi_{1}\right)}{t_{2}\left(t_{2}-2\left(p-\varphi_{2} d\right)\right)} & >\frac{Z_{1}}{Z_{2}}
\end{aligned}
$$

Proposition 8 is demonstrated. 


\section{ANNEX}

\section{Other cases (c et d) complementing Proposition 4, page 11.}

Proposition 9 c) A firm having adopted partial risk internalization with technology 1 turns to technology 2 while keeping partial risk internalization if:

$$
E \cdot\left(\varphi_{1}-\varphi_{2}\right)>\left(1-\varphi_{1}\right) \cdot \frac{p^{2}}{4 Z_{1}}-\left(1-\varphi_{2}\right) \cdot \frac{p^{2}}{4 Z_{2}}
$$

or

$$
E .\left(\varphi_{1}-\varphi_{2}\right)>\left(1-\varphi_{1}\right) Z_{1}\left(y_{1}^{L L+}\right)^{2}-\left(1-\varphi_{2}\right) Z_{2}\left(y_{2}^{L L+}\right)^{2}
$$

d) A firm having adopted full risk internalization with technology 1 turns to technology 2 and partial risk internalization if:

$$
p\left(1-\varphi_{2}\right) y_{2}^{L L+}-p\left(1-\varphi_{1}\right) y_{1}^{L L-}>2 \varphi_{2} E
$$

\section{Proof.}

For case c), we have to compute $E\left[\pi\left(y_{1}^{L L+}\right)\right]<E\left[\pi\left(y_{2}^{L L+}\right)\right]$, that is:

$$
\left(1-\varphi_{1}\right)\left(p y_{1}^{L L+}-Z_{1}\left(y_{1}^{L L+}\right)^{2}+E\right)-\left(1-\varphi_{2}\right)\left(p y_{2}^{L L+}-Z_{2}\left(y_{2}^{L L+}\right)^{2}+E\right)<0
$$

By replacing $y_{1}^{L L+}$ and $y_{2}^{L L+}$ by their value given by Equ. (6), and after simplification and arrangement,we have:

$$
E \cdot\left(\varphi_{1}-\varphi_{2}\right)>\left(1-\varphi_{1}\right) \cdot \frac{p^{2}}{4 Z_{1}}-\left(1-\varphi_{2}\right) \cdot \frac{p^{2}}{4 Z_{2}}
$$

or

$$
\text { E. }\left(\varphi_{1}-\varphi_{2}\right)>\left(1-\varphi_{1}\right) Z_{1}\left(y_{1}^{L L+}\right)^{2}-\left(1-\varphi_{2}\right) Z_{2}\left(y_{2}^{L L+}\right)^{2}
$$


For case d), we must compute $E\left[\pi\left(y_{1}^{L L-}\right)\right]<E\left[\pi\left(y_{2}^{L L+}\right)\right]$, that is:

$$
\begin{aligned}
\left(p-\varphi_{1} d\right) y_{1}^{L L-}-Z_{1}\left(y_{1}^{L L-}\right)^{2}+E-\left(1-\varphi_{2}\right)\left(p y_{2}^{L L+}-Z_{2}\left(y_{2}^{L L+}\right)^{2}+E\right) & <0 \\
\frac{\left(p-\varphi_{1} d\right)^{2}}{2 Z_{1}}-\left(1-\varphi_{2}\right) \cdot \frac{p^{2}}{2 Z_{2}}-\frac{\left(p-\varphi_{1} d\right)^{2}}{4 Z_{1}}+\left(1-\varphi_{2}\right) \cdot \frac{p^{2}}{4 Z_{2}}+\varphi_{2} E & <0 \\
\frac{\left(p-\varphi_{1} d\right)^{2}}{4 Z_{1}}-\left(1-\varphi_{2}\right) \cdot \frac{p^{2}}{4 Z_{2}}+\varphi_{2} E & <0 \\
Z_{2}\left(p-\varphi_{1} d\right)^{2}-\left(1-\varphi_{2}\right) Z_{1} p^{2}+4 Z_{1} Z_{2} \varphi_{2} E & <0 \\
p\left(1-\varphi_{2}\right) y_{2}^{L L+}-\left(p-\varphi_{1} d\right) y_{1}^{L L-} & >2 \varphi_{2} E
\end{aligned}
$$

\section{References}

[1] Alexander, J.C. (1992), "Unlimited shareholder liability through a procedural lens", Harvard Law Review, Volume 106, No. 2, p 387-445.

[2] Beard, T.R. (1990), "Bankruptcy and Care Choice", Rand Journal of Economics, Volume 21, pp 626-34.

[3] Boyd and Ingberman (1994), "Noncompensatory Damages and Potential Insolvency", The Journal of Legal Studies 23(2), pp 895-910.

[4] Boyd and Ingberman (1997), "The Search for Deep Pockets: Is 'Extended Liability' Expensive Liability?", Journal of Law, Economics and Organization vol 13(1), pp 232-258.

[5] Boyer, M. and Laffont, J.J. (1997), "Environmental Risks and Bank Liability", European Economic Review, Volume 41, pp 1427-59.

[6] Dionne, G. and Spaeter, S. (2003), "Environmental risk and extended liability: The case of green technologies", Journal of Public Economics, Volume 87, p 1025-1060.

[7] Easterbrook, F.H. and Fischel, D. R. (1985), "Limited Liability and the Corporation", The University of Chicago Law Review, Vol 52(1), pp 89-117. 
[8] Faure, M. (1995), "Economic models of compensation for damage caused by nuclear accidents: some lessons for the revision of the Paris and Vienna Conventions", European Journal of Law and Economics, Volume 2, pp 21-43.

[9] Fischer, C. Parry, I.W.H. and Pizer, W.A. (2003), "Instrument choice for environmental protection when technological innovation is endogenous", Journal of Environmental Economics and Management, Volume 45, Issue 3, p 523-545.

[10] Grundfest, J.A. (1992), "The Limited Future of Unlimited Liability : A Capital Market Perspective", The Yale Law Review, Volume 102, No. 2, p 387-425.

[11] Halpern, P., Trebilcock, M., and Turnbull, S. (1980), "An Economic Analysis of Limited Liability in Corporation Law", University of Toronto Law Journal, Volume 30, No. 2, p 117-150.

[12] Hansmann, H. and Kraakman, R. (1991), "Toward Unlimited Shareholder Liability for Corporate Torts", The Yale Law Review, Volume 100, No. 7, p 1878-1934.

[13] Hiriart, Y. and Martimort, D. (2006), "The Benefits of Extended Liability", Rand Journal of Economics, Volume 37, Issue 3, pp 562-582.

[14] Klimek, J. (1990), "Liability for Environmental Damages in Insolvencies: Bulora, Panamerica and Lamford", Journal of Environmental Law and Practice, Volume 2, pp 257-269.

[15] Magat, W.A. (1978), "Pollution Control and Technological Advance: A Dynamic Model of the Firm", Journal of Environmental Economics and Management, Volume 5, Issue 1, p 1-25.

[16] Magat, W.A. (1979), "The Effects of Environmental Regulation on Innovation", Law and Contemporary Problems, Volume 43, Issue 1, p 4-25.

[17] Milliman, S.R. and Prince, R. (1989), "Firm incentives to promote technological change in pollution control", Journal of Environmental Economics and Management, Volume 17, Issue 3, p 247-265. 
[18] Parry, I.W.H. (1995), "Optimal pollution taxes and endogenous technological progress", Resource and Energy Economics, Volume 17, pp 69-85.

[19] Pitchford, R. (1995), "How liable should a lender be? The case of judgment-proof firms and environmental risks", American Economic Review, Volume 85, p 11711186.

[20] Requate, T. (1998), "Incentives to innovate under emission taxes and tradeable permits", European Journal of Political Economy, Volume 14, p 139-165.

[21] Schmitt, A. and Spaeter, S. (2007), "Risque nucléaire civil et responsabilité optimale de l'opérateur", Revue Economique, Volume 58(6), pp. 1331-1351.

[22] Shavell, S. (1980), "Unlimited Liability Versus Negligence", The Journal of Legal Studies, Volume IX, Issue 1, p 1-25.

[23] Shavell, S. (1986), "The Judgment Proof Problem", International Review of Law and Economics, Volume 6, No. 1, p 45-58.

[24] Shavell, S. (2004), Foundations of Economic Analysis of Law, Harvard University Press. 


\section{Documents de travail du BETA}

2010-01 The Aggregation of Individual Distributive Preferences through the Distributive Liberal Social Contract : Normative Analysis

Jean MERCIER-YTHIER, janvier 2010.

2010-02 Monnaie et Crise Bancaire dans une Petite Economie Ouverte Jin CHENG, janvier 2010.

2010-03 A Structural nonparametric reappraisal of the $\mathrm{CO}_{2}$ emissions-income relationships Theophile AZOMAHOU, Micheline GOEDHUYS, Phu NGUYEN-VAN, janvier 2010.

2010-04 The signaling role of policy action

Romain BAERISWYL, Camille CORNAND, février 2010.

2010-05 Pro-development growth and international income mobility: evidence world-wide Jalal EL OUARDIGHI, mars 2010.

2010-06 The determinants of scientific research agenda: Why do academic inventors choose to perform patentable versus non-patentable research?

Caroline HUSSLER, Julien PENIN, mars 2010.

2010-07 Adverse Selection, Emission Permits and Optimal Price Differentiation Mourad AFIF, Sandrine SPAETER, mars 2010.

2010-08 The impact of ambiguity on health prevention and insurance Johanna ETNER, Sandrine SPAETER, mars 2010.

2010-09 Equité du plaider coupable : une analyse économétrique dans trois tribunaux de grande instance français.

Lydie ANCELOT, mars 2010.

2010-10 Networks, Irreversibility and Knowledge Creation.

Patrick LLERENA, Muge OZMAN, mars 2010.

2010-11 Les clusters et les réseaux comme fondements de la dynamique d'innovation dans l'industrie biopharmaceutique

Marc Hubert DEPRET, Abelillah HAMDOUCH, avril 2010.

2010-12 Large-scale risks and technological change: What about limited liability?

Julien JACOB, Sandrine SPAETER, avril 2010.

La présente liste ne comprend que les Documents de Travail publiés à partir du $1^{\mathrm{er}}$ janvier 2010. La liste complète peut être donnée sur demande.

This list contains the Working Paper writen after January 2010, 1rst. The complet list is available upon request. 